\title{
Learning during the COVID-19 Pandemic
}

\section{The Use, Features and Acceptance of Digital Learning Tools}

\author{
Aisha Futura TÜCHLER \\ Laboratory for Perceptual and Cognitive Systems, \\ Faculty of Computing, University of Latvia, \\ 19 Raina Blvd., Riga, LV-1586, Latvia \\ aisha.tuechler@lu.lv
}

\begin{abstract}
Dealing with digital learning tools has become our new daily routine, as the COVID19 pandemic restricts our mobility and limits our social contacts. Despite the omnipresence of the topic, little is known about how students experience distance learning with digital learning tools, how they evaluate the tools' features, as well as their advantages and disadvantages. An online survey was distributed in a Latvian higher education institution in late autumn 2020, and data of 104 students, both from Bachelor as well as from Master studies of the University of Latvia, were collected. The results of the present study highlight that motivation and engagement, as well as communication and interaction are important factors with regards to students' perceptions of and attitudes towards the distance learning mode. This exploratory research provides first evidence of perceptions and attitudes of Latvian university students concerning distance learning during the COVID-19 pandemic.
\end{abstract}

Keywords: learning, COVID-19, digital learning tools

\section{The impact of the COVID-19 pandemic on the education sector}

After its first discovery in late 2019, the novel coronavirus (SARS-Cov2) caused a global health crisis, later declared a pandemic by the World Health Organisation (World Health Organization, 2020). This then led states around the world to adopt a variety of measures to limit the spread of the novel coronavirus, such as the implementation of different social distancing measures, travel restrictions, as well as partial or complete lockdowns. These measures evidently also affected the education sector, and resulted in closures of schools and higher education institutions. Learners continued education from a distance. According to data from the United Nations Educational, Scientific and Cultural Organization (UNESCO), at the peak of the pandemic in April 2020, country-wide school and higher education institution closures were registered in 172 countries, affecting $84.8 \%$ of the total enrolled learners worldwide (UNESCO, 2021). 
Consequently, with classes being taught from a distance, the last months have seen drastic and unforeseeable changes and transformations in the educational field, affecting almost 1.5 billion learners around the world (UNESCO, 2021). The present research aims to contribute to the still sparse body of knowledge with regards to learning in times of the COVID-19 pandemic by examining the Latvian student population.

\subsection{The Latvian case}

The first documented case of the novel Coronavirus (SARS-Cov2) in Latvia was registered on March $2^{\text {nd }}, 2020$ in the capital Rīga (Public Broadcasting of Latvia, 2020a). Newly detected cases were increasing rapidly and in order to contain the spread of the virus and, similar to other countries in Europe and worldwide, schools and higher educational institutions throughout Latvia were closed (Public Broadcasting of Latvia, 2020b). After months of rather low incidence rates in May and June 2020, however, the lifting of measurements was introduced, and Latvia saw a rise of incidence rates of the novel coronavirus throughout the summer months. The changed situation, however, did not have an impact on the opening of educational institutions in autumn 2020, and Latvian pupils of all grades, as well as university students started the academic year $2020 / 21$ on site in their local school or higher education institution. This approach was then altered a few months into the new academic year, due to rapidly rising numbers of infections with the novel coronavirus, and the government adopted measures to limit the spread of the virus. Universities and other educational institutions were then closed and learning continued from a distance with the help of a variety of digital learning tools. Dealing with those tools has thus become a daily routine for learners, as the COVID-19 pandemic restricts their mobility and limits social contacts. The last months have shown that shifting to online classes and continuing learning with the help of digital tools is possible. But is it also desirable? Despite the omnipresence of the topic, little is known about how students experience distance learning with digital learning tools, and how the tools themselves are perceived.

\subsection{From digital learning to distance learning - some definitions}

In the scope of this research, an inclusive definition of digital learning tool is employed. All tools and technologies that facilitate and/or aid the learning process (Anohina, 2005; Mei et al., 2019), and are encoded in digital formats are considered to be digital learning tools. For the purpose of this study, the tools are not required to be employed online to be considered digital learning tools, although the majority are. Moreover, the tools do not have to be designed specifically for learning purposes, such as for instance social media like WhatsApp, or multimedia sources like YouTube. Once these tools are used for learning purposes, they are considered digital learning tools.

With growing body of evidence on the topic of learning during the COVID-19 pandemic, a multitude of conventions have arisen with regards to terminology. In the literature, the learning mode in place is referred to as online learning (Crawford et al., 2020), e-learning (Aboagye et al., 2021; Gonzalez et al., 2020), emergency online learning (Aguilera-Hermida, 2020), online teaching (Bao, 2020), emergency remote teaching 
(Iglesias-Pradas et al., 2021), as well as distance and remote learning (Daniela et al., in press), amongst others. Despite loan terms such as online learning, and e-learning emerging as widely used in the literature, there is no consensus amongst researchers about the meaning of these terms with reference to the current changes and transformations in the educational field (Hodges et al., 2020; Bao, 2020; Chen et al., 2020; Aboagye et al., 2021), and terminology development is still ongoing and definitions negotiated.

Very early into the current health crisis, Hodges et al. (2020) proposed a terminology to designate the mode of delivery of learning content in these unprecedented circumstances: Emergency Remote Teaching (ERT). They defined ERT as the "temporary shift of instructional delivery to an alternate delivery mode due to crisis circumstances" (Hodges et al., 2020, p.15). This approach distinguishes itself clearly from conventional online learning, which precedes a careful planning process taking into account the circumstances of educators and learners, such as class size, chosen pedagogy, pacing, and assessment strategy, amongst others, and hence requires this new and telling terminology. However, for the timeframe where the present research was conducted, the term Emergency Remote Teaching could potentially be misleading when designating the learning mode that learners and teachers were subject to, as some universities were preparing for the scenario of closures of educational institutions and had contingency plans in place. The implemented learning mode was hence not purely a result of an emergency, but - even if not completely laid out for this method of delivery was modified accordingly. For the scope of the present research, hence, ERT is not regarded as adequate terminology, and to prevent misconceptions and misunderstandings, was disregarded and another carefully selected. Following the classification proposed by Anohina (2005), the terminology used to denote the learning circumstance of Latvian students during the COVID-19 pandemic in the present article is 'distance learning'. Distance learning refers to learning contents being delivered remotely, with learner and teacher being geographically separated. This accurately describes the students' learning circumstances in autumn 2020 as, at the time of data collection, social distancing practices were in place in Latvia, and learners and teachers were not in the same location when education was delivered. Additionally, the term, as suggested by Anohina (2005), does not specify a medium, method or technology that is used for education delivery, hence it can include on- and offline learning as well as synchronous and asynchronous learning, as it encompasses many different techniques and and tools used, some more common to learners and teachers, some novel. Anohina (2005) also specifies both teacher and learner as important factors of the learning process, rather than presuming to heavily rely on technology constituting a central part in the process. Moreover, distance learning does not categorically exclude possible on-site contacts between learner and teacher, which accurately reflects the circumstances of the autumn term at Latvian universities. The terms 'distance learning' and 'remote learning' are used synonymously in the context of the present research. 


\subsection{Review of the literature on teaching and learning during the COVID-19 pandemic}

The literature concerning teaching and learning in the higher education sector in the course of the COVID-19 pandemic can be classified into three categories: The first category entails publications with a descriptive and evaluative approach, where online teaching strategies and/or learning tools are described and/or evaluated, the second comprises publications focusing on student's attainment, and third category encompasses publications with focus on students' perceptions, and experiences of learning during the COVID-19 pandemic. The present overview includes publications from the Western Pacific region, the South-East Asian region, North America and Europe, aiming for maximum comprehensiveness and representativeness. The global perspective was chosen as, albeit possible different conditions and education systems might prevail in the respective countries, the circumstance that usual procedures and processes were disrupted, and a swift and encompassing shift to another delivery format, namely the distance learning mode, had to be implemented unites the presented publications. The selected literature refers to learning in the time period from March to May 2020, the term Emergency Remote Teaching and Learning will hence be used if utilised in the respective publications.

\subsection{The descriptive-evaluative approach}

Crawford et al. (2020) extracted and compared the measures taken by higher education institution globally by analysing government communications, higher education news outlets, as well as other media sources from 20 representative countries. The authors provide an overview of mitigation strategies of a balanced sample of countries around the world, which is, however, limited to the operational and technical actions taken. By comparing the different approaches, it could be shown that response to the health emergency was not uniform across the globe, and a multitude of measures were employed. With a case analysis of instruction strategies to be taken by faculty staff, Bao (2020) gives a detailed overview of a process of transition to large-scale online education of a big Chinese university (Peking University). The publication highlights the necessity to adjust learning quantity, content and duration according to students' capabilities, and the necessity to provide support in form of regular and timely communication with students, as well as to foster their participation in online classes. Additionally, student's mental health and possible psychological impacts of the current health crisis is emphasised as aspect to be taken into account. Chen et al. (2020) performed an analysis of the most commonly used digital learning tools in China, with a special focus on the learners' perspectives and satisfaction. Conducting a survey study including middle and high school students, as well as college students, they found that platform availability, entailing ease of use, interface design, learnability, and the existence of a learning record, is the most important factor with regards to user satisfaction. Individual factors, such as frequency of use, educational level, satisfaction tendency, and platform choice were not found to have a significant impact on user satisfaction with the digital learning tools in use. In the Latvian context, a similar analysis was performed, albeit focusing on expert's evaluation of learning platforms for pupils (Daniela, Rūdolfa, \& Rubene, 
in press). The study assessed digital learning materials according to their educational value, their information architecture, their design as well as their access and usability and found that the examined learning tools scored high with respect to design, but markedly weaker ratings of interactivity and educational value were attributed to the assessed tools. Access and usability, entailing ease of access and interconnectivity of the tools, was the lowest rated set of criteria. The overall lowest rating was awarded to communication with the student, indicating that a two-way communication between educators and learners was not possible with the majority of the tools analysed.

\subsection{Focus on student attainment}

In their study, comparing attainment of students at a Spanish university in three consecutive academic years, Gonzalez et al. (2020) conclude that autonomous learning performance of students during the time of the confinement in 2020 significantly improved. They employed a field experiment with 458 students from different fields of study, comparing an experimental group to control groups which were not subject to obligatory distance learning. Additionally, they indicate that the effect is also significant in courses that did not change their format when performed during the confinement. However, p-values were not corrected for multiple comparisons, the conclusions are hence to be taken with precaution. In another case study carried out at the School of Telecommunication Engineering at Universidad Politécnica de Madrid in Spain (Iglesias-Pradas et al., 2021) investigated the impacts of the distance learning mode on students' attainment, in the light of instructional decisions taken by educators implementing Emergency Remote Teaching. By comparing the results of Bachelor's students in 43 different courses over three academic years 2017/18 to 2019/20, they could show that overall performance of students was significantly improved in the academic year 2019/20. This goes in line with findings of Gonzalez et al. (2020), hinting towards a positive effect of distance learning on students' attainment. Additionally, Iglesias-Pradas et al. (2021) could show that the choice of digital learning tools, class size or method of delivery did not have a significant impact on the student's attainment during remote learning. Interestingly, in their study, students' attitudes, as perceived by educators, were negatively associated with attainment, meaning that improvement seemed to be greater in courses where students' attitudes were perceived as worse. In a similar investigation, however, Bawa (2020) contrasts data of 207 students in the United States who were subject to ERT with 190 students who were not, and found no significant differences with regards to their attainment, hence, failing to confirm the findings of Gonzalez et al. (2020) and Iglesias-Pradas et al. (2021).

\subsection{How do students experience the time of distance learning?}

The third, and for the scope of the present study, specifically relevant category of publications is the one concerned with university students' experiences and attitudes with regard to distance learning mode. In addition to the analysis of student's attainment, Bawa (2020) analysed written comments by students and was able to extract 17 codified categories representing experiences of the ERT mode. The two by far most prevalent categories paint a picture whose interpretation is not straightforward: students most 
commonly find the transition from on-site to emergency remote learning very difficult, but, at the same time, have a positive attitude toward their increased individual responsibility. Other categories refer to the challenges and shortcomings associated with ERT, as the difficulty to consume online materials provided, as well shortcomings concerning the structure of the content and impeded collaboration. Then again, other categories refer to positive experience of students who perceived the ERT to be surprisingly better, as well as reports of more flexibility and increased productivity. The investigation by Rahiem (2020), qualitative-phenomenological study of students' perceptions of the implementation of "Emergency Remote Learning" in tertiary education in Indonesia, could also evidence these diverging perceptions. The analysis of diaries, essays and focus group discussions revealed that students were subject to blended strategies and concepts, including e-learning, m-learning, and conventional learning techniques. The focus of this contribution was both on the method of educational delivery, as well as the learner's experience in the process. Students reported both positive and negative experiences, which was termed "paradoxical" by the author (Rahiem, 2020, p.8). Students experienced greater flexibility, and hence better time management, but also an overload of tasks, leading to worse time management, then again, learning was experienced as more tiring, but also allowed for more breaks and possibilities for resting.

A survey study (Aboagye et al., 2021) identified several factors with regards to challenges Ghanaian students face with regards to the distance learning mode. The factors that emerged were social issues, including communication and individual issues, such as isolation; lecturer issues, referring to issues with learning material and methods employed by educators; academic issues; as well accessibility issues comprising problems with technical equipment and internet connection. Accessibility issues were found to be the most common issues, followed by social issues. In a similar study aiming to explore students' attitudes, self-efficacy, and cognitive engagement as well as challenges and positive aspects of the distance learning mode during the COVID-19 pandemic, Aguilera-Hermida (2020) conducted survey with 279 predominantly undergraduate students in the United States. The results of this study indicate that the students' cognitive engagement and self-efficacy shaped their attitude towards the learning mode in place, meaning that students who reported lower cognitive engagement and self-efficacy were more in favour of face-to-face learning, whereas those who were more cognitively engaged and had a higher self-efficacy, found themselves to have a more positive attitude towards remote learning. Items assessing change of self-efficacy included statements about the ability to complete assignments on time and to be successful in classes, as well as time management and knowledge of new tools. Cognitive engagement entailed items about grades, knowledge and learning, as well as concentration, engagement, interest and enthusiasm. The qualitative data analysed by Aguilera-Hermida (2020) reveal that the online learning mode was rated as an unpleasant experience with students perceiving it as more difficult, and report lacking necessary resources supporting learning (such as libraries, or interaction with educators), difficulties with focus and motivation, as well as stress and anxiety. Additionally, students experienced education to be of decreased quality. With regards to positive aspects, more family time and the ability to catch up on before neglected activities such as hobbies or learning new skills 
were mentioned. Compared to the comments about challenges, however, those about positive aspects were fewer, with some students even completely negating the presence of positive aspects. Aguilera-Hermida (2020) concludes that students overall preferred face-to-face over remote online education and students' self-reported motivation, selfefficacy, and cognitive engagement decreased in the time of remote learning. Another important finding is that negative attitude towards the online learning mode negatively influences motivation, cognitive engagement and self-efficacy of students, and viceversa, potentially impacting their learning success.

The present exploratory research aims to tackle the following research questions: What are the digital learning tools used by Latvian university students, and how often are they used? How did their frequency of use change, as compared to before the first distance learning period in spring 2020? What are the features of the digital learning tools in use? How is the student's overall attitude towards the distance learning mode, and how are its advantages and disadvantages perceived? Are there unmeet needs of students during the time of distance learning, and if so, which are they? How do student perceive their attainment in times of distance learning?

\section{Methods}

An online survey was developed to explore the frequency of use of digital learning tools, their features (like degree of interactivity, their efficiency and effectiveness, amongst others) as well as their acceptance amongst Latvian students. Furthermore, student's attitudes towards the distance learning mode, and their experienced attainment were assessed. The survey was created and hosted on QuestionPro ${ }^{\mathrm{TM}}$, a survey platform for designing and distributing questionnaires.

The survey was made up of 35 questions, comprising over 90 items in total. The final number of presented questions and items depended on the participant's answers, as for some questions, an affirmative answer was prerequisite for the display of further questions. The survey covered questions regarding digital learning tool use, features of digital learning tools, their acceptance, as well as demographic information about the participants. The survey contained a mix of closed and open-ended items, at a ratio of 9 to 1 . The present research received ethics approval by the Scientific Research Ethics Commission of the Institute of Cardiology and Regenerative Medicine at the University of Latvia on November $11^{\text {th }}, 2020$.

\subsection{Frequency of use of digital learning tools}

To determine the frequency of use of digital learning tools, participants are presented with response options on a 7-point ordinal Likert scale with labels ranging from 'Never', to 'Every day'. Intermediate options reflect non-equidistant intervals of use that lie between the opposite frequency expressions, such as 'A few times per year', 'Once per month', 'Up to 3 times a month', '1-2 times a week' and 'Up to 6 times a week'. These 
response options were chosen to avoid shortcomings due to linguistic ambiguity and possibly differing individual interpretations of linguistic terms commonly used in 5point Likert scales, like 'Sometimes', 'Often', etc. (Bocklisch et al., 2012; Bass et al., 1974; Newstead and Collis, 1987). A 7-point Likert scale was chosen due to evidence from several investigations suggesting that they are superior to scales with fewer points regarding both their reliability (Cicchetti et al., 1985; Preston and Colman, 2000), as well their acceptance by users (Preston and Colman, 2000).

\subsection{Features and acceptance of used digital learning tools}

Another variable of interest in the present survey are the features of the used digital learning tools. To identify these features and ascertain the degree of prevalence, participants were presented with statements about used learning tools and asked to indicate their agreement to the given statement. Examples of such statements are: 'They featured live videos of lecturers and peers', 'They featured exercises/tasks to be solved and provided feedback and tips', 'They enabled students to share files', etc. A visual analogue scale (VAS) was used to determine the participant's grade of agreement with given statements about features and acceptance of digital learning tools, their overall attitude, as well as advantages and disadvantages of digital learning tool use during the COVID-19 pandemic. Participants were asked to choose a point by moving a slider on a horizontal line that correctly maps their experience or attitude. The endpoints, or anchors, of the line were labelled 'Do not agree at all ('Pilnībā nepiekrītu' in Latvian), and 'Completely agree' ('Pilnībā piekrītu'). Only endpoints of the scale were labelled verbally to minimise the risk of central tendency and social desirability bias (Weijters et al., 2010). The response option 'I don't know' was added to increase the response rate, as suggested by Roster et al. (2015), and participants were instructed to not move the slider if they did not know, or did not want to answer the question.

A common problem with discrete 5- or 7-point Likert-type scales is the erroneous conception of their scaling, as they are often assumed to constitute interval scales (Jamieson, 2004). The distances between consecutive response options are presumed to be equal in commonly used Likert-scales, meaning that, for instance, the intensity of acceptance or agreement that lies between 'Strongly agree' and 'Agree' is considered to be the same as between 'Agree' and 'Disagree', in the case of a 4-point Likert scale. This assumption, however, is questionable. Using a VAS instead of a Likert scale not only results in being visually attractive and easy to use, but also ensures that the response options are truly symmetrical and the scale has interval character (Reips and Funke, 2008).

\subsection{Mixed Methods approach}

In addition to the survey, and with the aim to obtain a finer grained perspective on the phenomenon of digital learning tool use of Latvian students during the COVID-19 pandemic, qualitative interviews were conducted, and together with qualitative data of the survey, were analysed employing content analysis (Mayring, 2004) with the software RQDA (Huang, 2014). By combining qualitative and quantitative methods in a 
congruent way, the scope and comprehensiveness of this research could be expanded, and allows for deeper insights into the phenomenon in question. This mixed methods approach was chosen to simultaneously meet two objectives: With the quantitative survey, relationships between two or more variables can be illustrated, and described. By means of the qualitative interviews, it can be further explored how these relationships materialise. This approach allows for flexibility and openness, possibly evidencing relations and insights that were not anticipated (Morse, 2003). Combining case studies with survey data helps to understand the complex and multifaceted reality with regards to distance learning in the course of the COVID-19 pandemic.

\subsection{Sampling and analytical strategy}

The survey invitation was distributed via contact points at different faculties of the University of Latvia, and the link disseminated via the respective mailing lists. This approach was chosen to reach students of all the different fields of study at the university with the aim of having an illustrative sample representing the Latvian student population of different study fields. The participants voluntarily participated in the survey, and informed consent was obtained before the first survey item was displayed.

\section{Results}

104 university students gave informed consent and filled out the survey. They did not receive remuneration for participating. The data of respondents were analysed with IBM SPSS Statistics for Windows, version 22 (IBM Corp., Armonk, N.Y., USA). The mean age of respondents is 23.21 (SD 7.69). 58\% are female, $41 \%$ male and $1 \%$ indicated 'Other' as their gender. $87 \%$ of the sample are Bachelor students, $8 \%$ were Master students, and $6 \%$ stated they are enrolled in other study programmes such as professional Bachelors or programmes at a college ('Koledža').

Higher education in Latvia comprises both of academic, as well as professional study programmes. There are three cycles of higher education, namely first cycle or Bachelor, second cycle or Master and third cycle or Doctoral studies. Programmes in Medicine, Dentistry and Pharmacy are five- and six-year, respectively, and count as equal to Master's degrees (second cycle). The mentioned study programmes are provided by three different types of tertiary education institutions, namely university type institutions, non-university type institutions and colleges ('koledža').

The majority of respondents are students of Life sciences (45\%), followed by Mathematics (19\%) and Pedagogy (9\%). Students from fields like Engineering (6\%), Computer Science (5\%), Work and Environmental Protection and Expertise (Darba aizsardzība, 5\%), and Occupational Health and Safety (Arodveselība un drošība darbā, 5\%), as well as Humanities, Medicine, Statistics, Architecture, and Physics are also present in the sample. Compared to the general population of students in higher education in Latvia, this sample is biased towards Bachelor students (87\% in our sample, as opposed to $56 \%$ in the general population), and students of Natural Sciences, Mathematics and 
Computer Science, making up $71 \%$ of our sample, whereas in the general population they constitute merely roughly $10 \%$. It could, however, accurately reflect the gender distribution of students with 58\% females in our sample, as opposed to $56 \%$ in the general population of university students (Central Statistical Bureau, 2021).

Table 1. Sample composition

$\mathrm{n}=104$ university students in Latvia

\begin{tabular}{l|l|l}
\hline $\begin{array}{l}\text { Mean age } \\
\text { in years }\end{array}$ & \multicolumn{2}{|c}{$23.21(\mathrm{SD} 7.69)$} \\
\hline & 60 & $\%$ \\
\hline Gender & 43 & $57.7 \%$ \\
female & 1 & $41.4 \%$ \\
male & & $0.96 \%$ \\
other & 90 & \\
\hline Study level & 8 & $86.5 \%$ \\
Bachelor & 6 & $7.7 \%$ \\
Master & 50 & $5.8 \%$ \\
Other & 50 & $45.5 \%$ \\
\hline Fields of study & 21 & $19.1 \%$ \\
Life Sciences & 9 & $8.2 \%$ \\
Mathematics & 7 & $6.4 \%$ \\
Pedagogy & 6 & $5.4 \%$ \\
Engineering & 4 & $3.6 \%$ \\
Computer Science & 3 & $2.7 \%$ \\
Humanities & 7 & $9.1 \%$ \\
Medicine & &
\end{tabular}

\subsection{Change of behaviour of students}

Students were asked if the noticed a change in their behaviour, as compared to beginning of the autumn term, where all their classes were on-site. The majority of students showed agreement with the statement that it is harder to focus at the task at hand at home, the mean value of the slider placements being 66.62 (SD 27.36) out of 100, and making it the most agreed-on statement in this section. With values under 20 out of 100 points, less than $10 \%$ of university students rather not agreed or completely disagreed with the statement, whereas another $19 \%$, on the contrary, completely agreed, placing the slider on 100 out of 100 points. Around 5\% students indicated that they do not know, or do not want to answer the question. Similarly, students rather agreed they were less motivated/engaged than in regular classes in university, with a mean value of slider placement at 63.28 (SD 26.36). Nevertheless, there are also students who experienced being more motivated, placing the slider on values higher than 75 out of 100 . They are, however, the minority, constituting only roughly $10 \%$ of the sample. Almost $10 \%$ students indicated that they do not know or do not want to answer the question. 


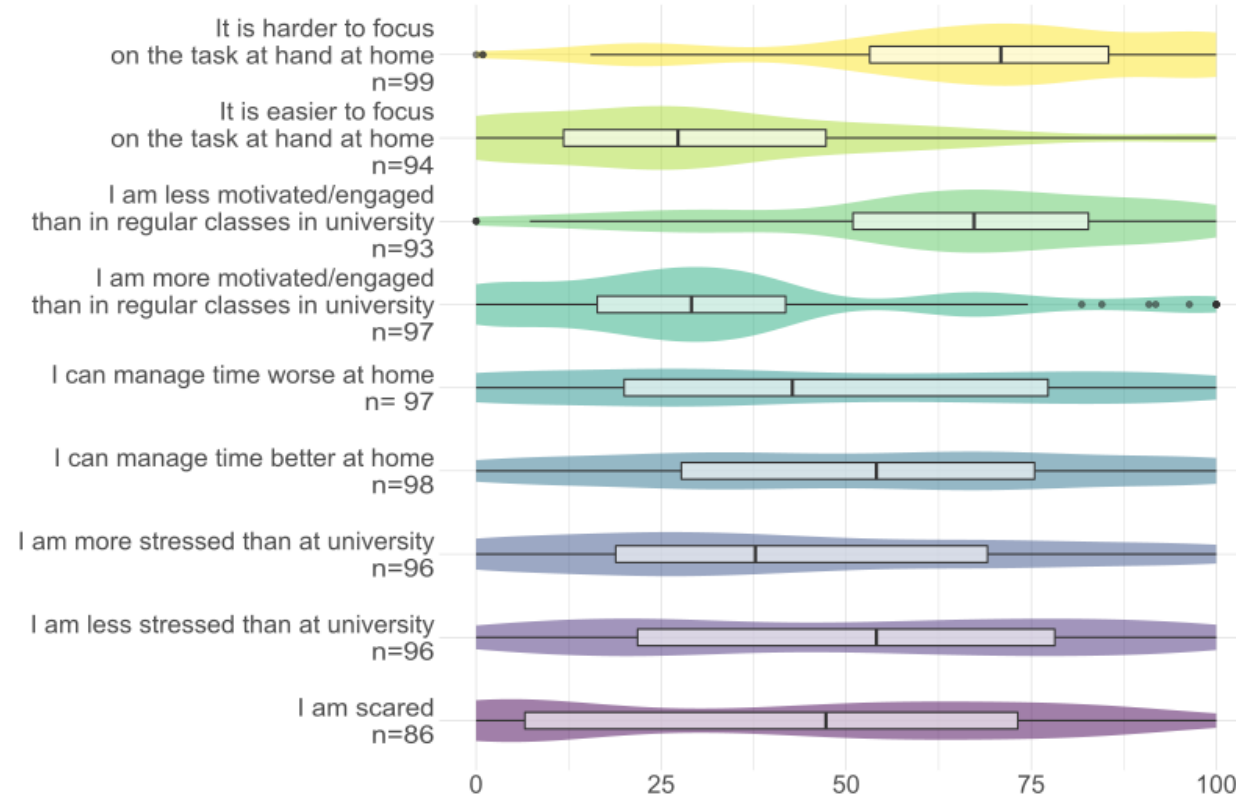

Fig. 1. Observed change of behaviour of students

Verbal anchors 'Do not agree at all' at 0 and 'Completely agree' at 100

\subsection{Correlations to overall experience with distance learning mode}

In order to assess their satisfaction, students were asked to indicate their overall experience with the current distance learning mode by slider placement. The anchor points were 'Very unsatisfied' and 'Very satisfied', the former having an underlying value of 0 , the latter 100 .

The mean value of overall experience rating was 53.43 (SD 27.00), hinting towards only weak positive perception of the distance learning mode amongst Latvian students in the sample. In the three most represented study programmes, students of Life sciences (45\% of the sample) showed the highest mean satisfaction values (57.30, SD 25.55), followed by students of Pedagogy (53.43, SD 26.99), constituting $9 \%$ of the sample, and were lowest in Mathematics students (19\% of the sample) with a mean value of 42.37 (SD 25.55).

Higher ratings of overall satisfaction with the distance learning mode are associated with a better focus on tasks at hand, better time management and motivation. There are strong correlations between overall satisfaction ratings and agreement to statements concerning better time management $(\mathrm{r}=0.698)$, better focus on the task at hand $(\mathrm{r}=0.605)$, as well as higher motivation and engagement $(\mathrm{r}=0.483$, all $\mathrm{p}<0.01)$. Worse 
time management and motivational issues are most strongly associated to lower ratings of overall satisfaction with the distance learning mode. The agreement to the statement that time management has worsened while learning from a distance is strongly negatively correlated to overall satisfaction rating $(\mathrm{r}=-0.643)$, and so is agreement to being less motivated/engaged than in regular classes at university $(r=-0.597$, both $p<0.01)$.

\subsection{Digital learning tool use in times of distance learning}

University students in our sample most commonly use digital learning tools which feature live online teaching during times of distance learning. More than three quarters of the respondents, namely 76\%, stated that they use tools like Microsoft Teams or Zoom between 3 and 7 times a week. Social media for learning purposes are similarly popular during the time of distance learning, with $35 \%$ stating that they use it daily, and $19 \%$ using it up to 6 times a week. More than half of the respondents state that they use it frequently, meaning between 3 and 7 days a week.

With $54 \%$ of university students indicating that they use WhatsApp for learning more than twice a week, of which $26 \%$ use it daily, it is the application of choice, rather than Facebook, with only $6 \%$ using it at least 3 times a week and $75 \%$ stating they never use it. $45 \%$ of university students use video lectures of university professors or lecturers between 3 to 7 times a week, whereas a quarter of respondents use them 1-2 times a week, and only $9 \%$ use them daily.

Almost half of the respondents state that they do not use learning platforms like Moodle during the time of distance learning, with only $9 \%$ using it on a daily basis, and around 25\% using it 1 to 6 times a week. (Note: The University of Latvia's Moodlebased system is called E-studijas, which might have led to some confusion and lower estimates of learning platform use. The provided information about frequency of use is therefore to be treated with caution). The vast majority, namely $67 \%$ state that they never use Massive Open Online Courses (MOOC) for learning, whereas 7\% use it at least once per week. Live online teaching is the most commonly used method for Latvian students in times of distance learning, followed by use of multimedia content, and online learning materials provided by educational websites, whereas learning platforms are not widely used, according to students. The most frequently used tool category is social media for learning purposes, specifically WhatsApp. 


\section{Digital learning tool use}

$\mathrm{n}=104$ university students in Latvia

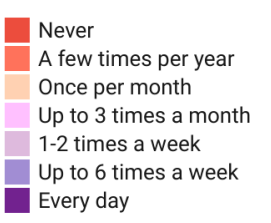

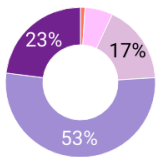

Live online teaching via Zoom, MS Teams

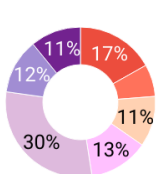

Online learning material provided by

specific websites

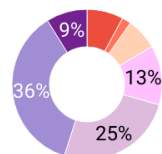

Videos of lectures of lectures of university professors an
lecturers

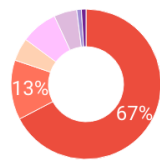

Online courses like Coursera, EdEX

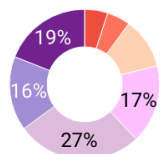

Videos or other multimedia content like YouTube or similar

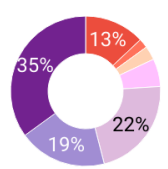

Social media for learning like WhatsApp, Facebook etc.

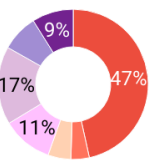

Learning platform like Moodle

Fig. 2. Digital learning tool use in autumn 2020

When asked which tools students in our sample used out of their own volition, the most commonly used tools that featured live online teaching, as well as videos and multimedia content with almost $70 \%$ and $60 \%$ of students using it at least once a week, respectively. The least common digital learning tool types were MOOC and learning platforms, such as Moodle, with $78 \%$ and $63 \%$ of respondents stating that they never use it. Surprisingly, roughly a third of respondents stated that they also use tools featuring live online teaching in their free time at least once a week. Videos of lecturers of university professors and lecturers, and online learning material provided by specific websites show a similar frequency of use.

The most commonly used tools in student's free time are, again, social media for learning and tools featuring videos or other multimedia content, with over $60 \%$ of respondents using them at least on a weekly basis. Social media are, however, most frequently used, with $40 \%$ of respondents using them 3 to 7 times a week, and almost a quarter of respondents using them daily.

The distance learning mode during the COVID-19 pandemic in autumn 2020 in Latvia has led to more digital learning tool use across all of the different learning tool types and categories, according to our survey data. 


\section{Digital learning tool use before spring 2020}

$\mathrm{n}=104$ university students

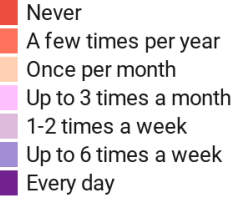

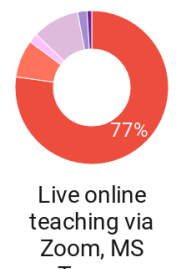
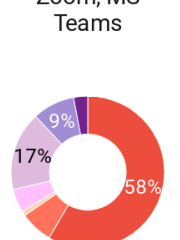

Online learning

$$
\text { material }
$$

provided by specific websites

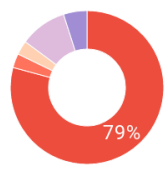

Videos of lectures of university professors and lecturers

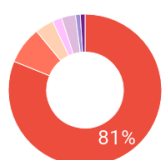

Online courses like Coursera, EdEX

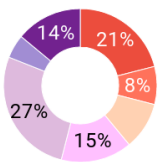

$15 \%$

Videos or other multimedia content like YouTube or similar

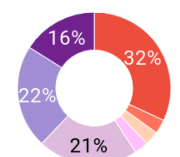

Social media for learning like WhatsApp, Facebook etc.

Fig. 3. Digital learning tool use before spring 2020

The most commonly used tool features Live online teaching, which could increase it frequency of use by five times from spring 2020, where $77 \%$ reported that they have never used digital learning tools for live online teaching. Similarly, Social media for learning purposes is used daily by $35 \%$, and $19 \%$ are using them up to 6 times a week. An increase of frequency of use of social media for learning can be evidenced, as the percentage of daily users increased from $16 \%$ to $35 \%$. Almost half of the respondents state that they do not use Learning platforms like Moodle during the time of distance learning in autumn 2020. Frequency of use has increased compared to values before spring 2020, however, with $47 \%$ never using learning platforms, it is still not the tool of choice for many. Videos of university professors or lecturers were fairly unpopular before spring 2020 , with only around $15 \%$ reporting to regularly have used them at least once per week. $79 \%$ of university students even reported to have never used them before spring 2020. These numbers, however, have drastically changed, where $70 \%$ report using them on a weekly basis in autumn 2020. Online learning material provided by specific websites has also seen a considerable increase of frequency of use, with more than half of the respondents reporting that they use such material at least once a week in autumn, as compared to only $25 \%$ before spring 2020 . Videos or other multimedia content remain popular (more than half reporting that the use them at least once per week), with a moderate increase of frequency of use compared to spring 2020. As for MOOC, $68 \%$ state that they never use such courses as provided by Coursera or EdEx 
and others, for learning. This is less than before spring 2020 (81\% stated they never used it), but not a substantial change.

\subsection{Features of digital leaning tools in use}

Students were also asked to indicate agreement to statements about features and functionalities of the digital learning tools in use. These features of tools will be reported in three different sections, entailing three categories for analytical purposes. The first category of analysis refers to the presentation and structure of content of the used digital learning tools, the second is concerned with communication and collaboration, including statements about interactivity and feedback, whereas the third category comprises of statements with regards to efficiency and effectiveness.

3.4.1 Presentation and structure The data on features of the tools in use when it comes to presentation and structure are rather inconclusive. The most agreed-on statement is that the tools in use featured live videos of their lecturers, but the mean value of agreement to the statement was only 53.82 (SD 31.40), followed by the presentation of multimedia content 52.99 (SD 29.50), and the statement that they presented the learning content in a more appealing way 50.22 (SD 27.63). The data are dispersed, and conclusions are not straightforward.

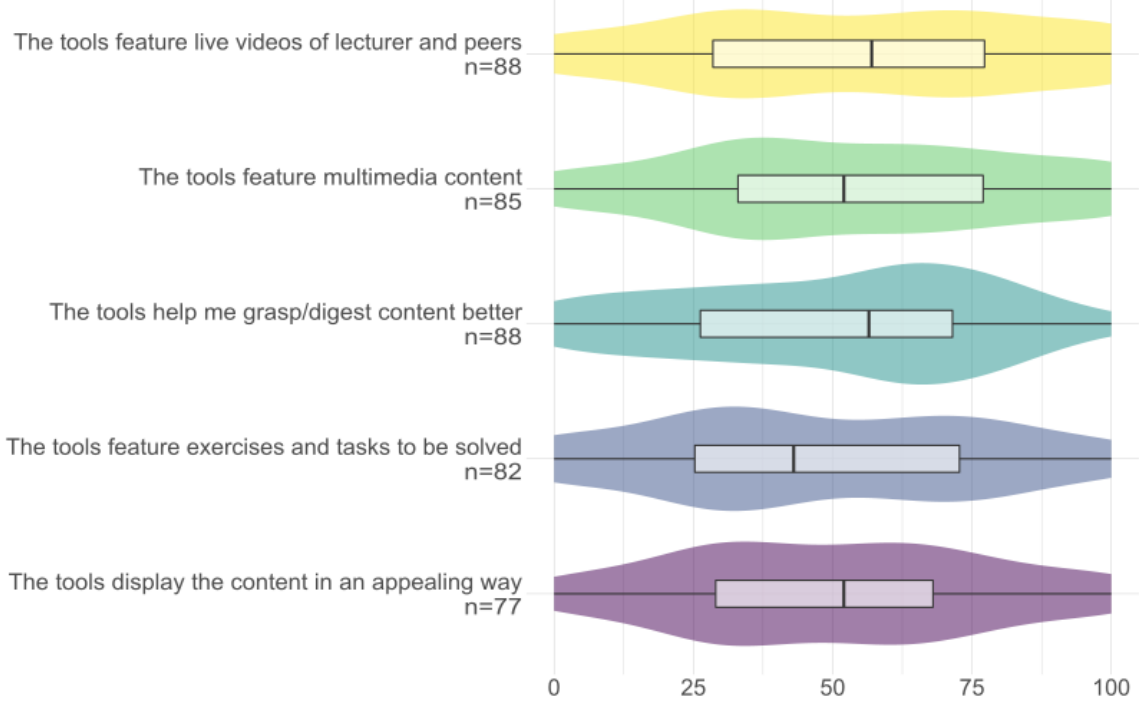

Fig. 4. Features of digital learning tools in use - Presentation and structure Verbal anchors 'Do not agree at all' at 0 and 'Completely agree' at 100 
3.4.2 Communication, collaboration and feedback The most agreed-on statement in the section of communicative and collaborative features of the learning tools in use is that the tools enable students to share files. $22 \%$ of respondents, however, indicated values of under 20 out of 100 , completely or rather disagreeing to the statement, whereas $30 \%$ rather or completely agreed, illustrating diverging experiences with the tools in use. The mean value of agreement to statements concerning fostering of communication and collaboration, as well as providing feedback range between 47.56 to 47.99, which can be interpreted as the average student being neutral to these statements, with a very week tendency of disagreeing. Around $20 \%$ of the sample (between 15 and 25 students) indicated that they do not know or do not want to answer the questions in this section. The least agreed-on statement in this section is that the tools feature exercises/task to be solved, and provided feedback and tips, with a mean value of 44.51 (SD 30.32).

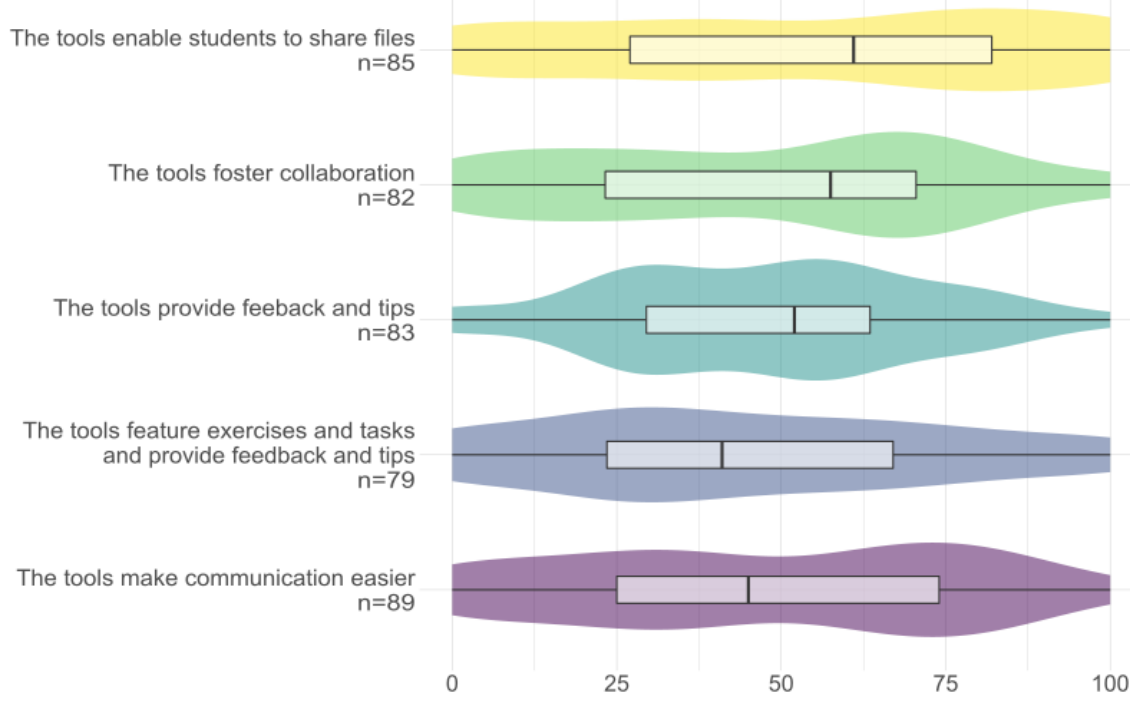

Fig. 5. Features of digital learning tools in use - Communication, collaboration and feedback Verbal anchors 'Do not agree at all' at 0 and 'Completely agree' at 100

3.4.3 Efficiency and effectiveness With regards to the features of the digital learning tools ensuring to accomplish learning goals without needless efforts, meaning their efficiency, as well as their ability to produce desired educational results, meaning their effectiveness, the results are not conclusive. Moreover, the values of agreement to all of the statement in this section show big dispersion with standard deviations between 27.96 and 32.24. This again, and similarly to other categories of analysis, indicates dif- 
ferent perceptions of students with regards to efficiency and effectiveness of the digital learning tools in use.

There is a weak tendency to agreeing to the statement that the tools in use help students to save time, the mean value of slider placement being 51.37 (SD 31.45). 20\% of students, however, completely or rather disagreed to the statement, placing the slider on values below 20 out of 100 . On the contrary, $20 \%$ rather or completely agreed to the statement, with slider values between 80 and 100 . Only around $20 \%$ rather or completely agree to the statement that they enjoy using the tools, placing the slider on values above 70 out of 100 , whereas roughly $30 \%$ rather or completely disagree, with slider placements below 30. The mean value of agreement to this statement is 48.63 (SD 28.36), showing a very week tendency towards disagreement.

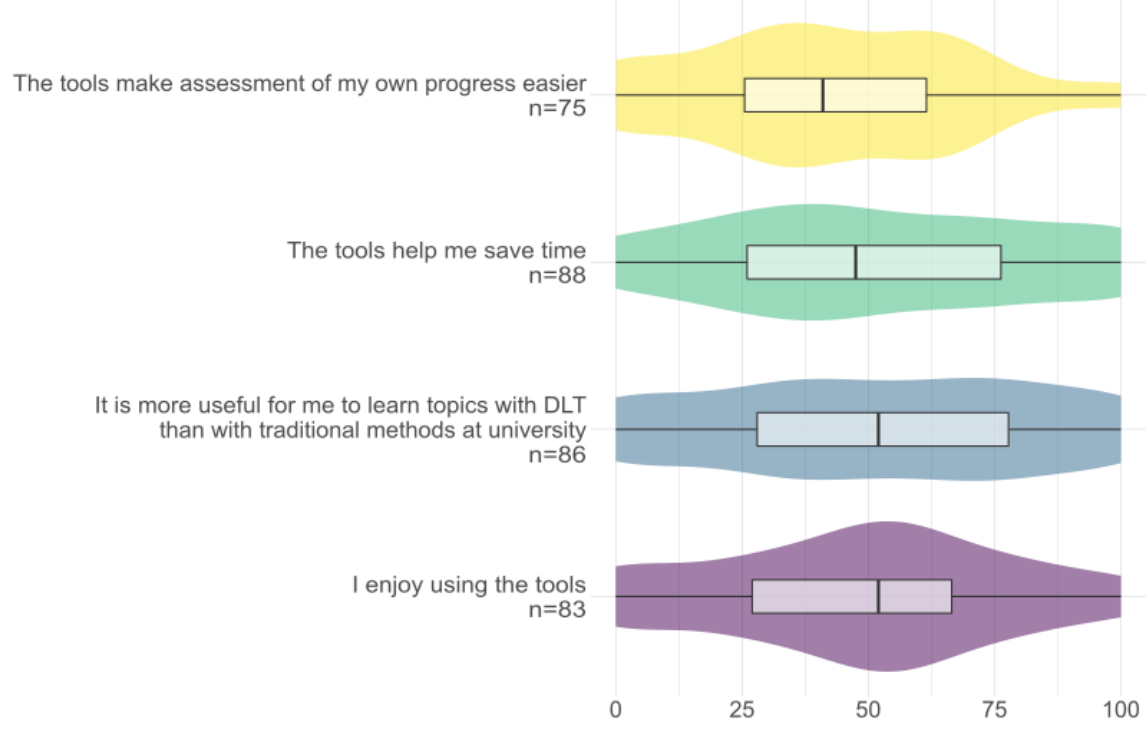

Fig. 6. Features of digital learning tools in use - Efficiency and effectiveness Verbal anchors 'Do not agree at all' at 0 and 'Completely agree' at 100

The two most agreed-on statements in this section are that it is more useful to learn topics with digital learning tools than with traditional methods at university, and that the tools help to save time, with mean values of 51.35 (SD 32.24) and 51.27 (SD 31.35), respectively. The least agreed-on statement in this section is that the tools make assessment of their own progress easier, with a mean value of 42.31 (SD 26.56). 
The most evident features of the digital learning tools in use refer to the facilitation of communication and collaboration, as well as the presentation and structure of content. The most agreed-on statement was the students were able to share files with the tools in use, followed by the tools featuring live videos of lecturers, and multimedia content. The students in our sample least agreed with statements concerning efficiency and feedback, mean agreement values being low with regards to statements about facilitated assessment of own progress and provision of feedback and tips for the learner. It becomes evident that, here again, communication and collaboration emerge as important aspects with respect to features of digital learning tools in use. The most agreed-on features of the tools in use contain this analytical category.

\subsection{Importance of digital learning tools for future education}

When asked how important digital learning tools be for their studies in the future, $36 \%$ of students in our sample stated that they will be extremely important, placing the slider on a value of 100 . More than $60 \%$ placed the slider on values between 80 and 100 , indicating that they ascribe high importance to these tools for their future education. Less than $10 \%$ indicated lower values than 60 out of 100 . The mean value of rated importance was 83.92 (SD 19.31). The vast majority, thus, is of like mind when judging importance of digital learning tools for their future education.

The situation of agreement is less clear, however, when it comes to the question if digital learning tools can aid students who fell behind in the time of distance learning. The average value of agreement to the statement is 53.35 (SD 30.50), and with the data showing great dispersion, indicates that there are diverging opinions on the matter. Whereas $12 \%$ state that these tools do not aid students who fell behind at all placing the slider on a value of 0 , and, on the contrary, $7 \%$ state that they completely do so. 20 students, so almost $20 \%$ of the sample, indicated that they do not know, or do not want to answer the question. Every second student in this survey (52\%) reported their skills falling behind during the time of distance learning. This perception is most pronounced in Mathematics students, with 59\% answering in affirmative. Among the skills that students mentioned they are falling behind in were solving practical tasks, acquisition of social skills, mathematical problem solving, as well as various professional skills, which cannot be implemented without face-to-face learning, like welding, confectionery, sewing. Also, deficits in communication and collaborative skills, as well as in exchanging experience and public speaking are stated. The lack of deep thought and understanding is also mentioned. Few students even commented falling behind in all skills, as distance learning could not well replace face-to-face classes at university. These data stem from comments that students of the present sample could voluntarily leave about skills they saw falling behind. Out of all comments, students of mathematics were the most frequent ones to comment, making up a third of statement providers.

\subsection{Needs of students in times of distance learning}

Another dimension of interest of this research are the needs of students during the time of distance learning in the course of the COVID-19 pandemic. Survey participants were 
asked to indicate agreement to possible communicative and institutional, but also technical obstacles that they might be faced with. In general, students rather disagreed with having unmet needs both in the institutional and the technical domain in the time of distance learning, with rather low agreement values for needs concerning digital skills and guidance, as well as technical equipment. The least agreed-on unmet need is the necessity of an own computer, with almost half of the sample completely negating this statement. However, for a non-negligible fraction of around $20 \%$ of respondents who rather or completely agreed with this statement, placing the slider on values between 80 and 100, having their own computer represented a need in the time of distance learning.

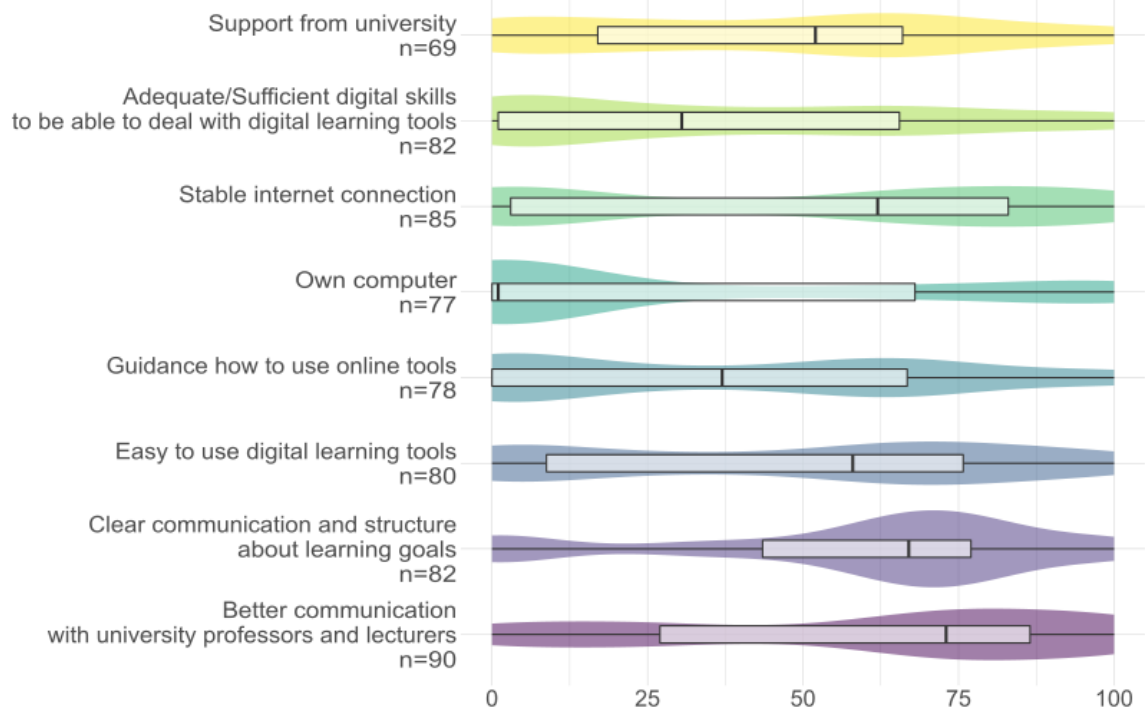

Fig. 7. Needs of students in times of distance learning Verbal anchors 'Do not agree at all' at 0 and 'Completely agree' at 100

Sufficient digital skills for dealing with the digital learning tools, as well as guidance to use these tools do not seem to be a problem for many, with mean values of agreement being merely 37.45 (SD 30.50) and 39.05 (SD 34.79), respectively. Then again, around $30 \%$ of students rather or completely agreed with the statement that better communication with university professors and lecturers is needed, placing the slider on values higher than 80 out of 100 , whereas only less than $20 \%$ placed the slider on values below 20. With a mean value of 60.20 (SD 34.45), this is indeed the most agreed-on statement in the section of needs of students, yet, the data show considerable dispersion. Similarly dispersed and agreed-on is the statement about missing clear communication and structure of learning goals, with a mean value of slider placement at 58.73 (SD 30.78). 20\% 
of students completely or rather disagreed with this statement, placing the slider on values above 80 , and another $20 \%$ completely or rather disagreed with slider values below 20 out of 100 . Roughly $7 \%$ of the whole sample agreed-on experiencing other needs than the ones indicated, placing the slider on values between 70 and 100, and leaving voluntary comments. The provided comments refer to needs concerning a more suitable and undisturbed working environment, as well as technical equipment like a better computer, or the availability of a scanner and needed computer programmes. Then again, other comments refer to needs concerning better interaction and communication with lecturers and peers, as well as internal factors such as the need for motivation.

Another indicator that gives account of students' needs is the number of respondents for each of the statement. Among the statements with mean agreement values over 50 out of 100 , this number was highest for the statement concerning communication with university professors and lecturers ( $87 \%$ of the sample), followed by the statement concerning clear communication and structure about learning goals (69\% of the sample). Apart from the answer 'Other', the lowest responds rate was detected for the statement about support from university, which almost $34 \%$ decided not to answer.

Students in the present sample indicate unmet needs with respect to communication, first and foremost concretely with their professors and lecturers, but also in general concerning communication about the structure of classes and learning goals. It is conspicuous that, again, communication seems to be central in like manner when analysing the needs of university student in the time of distance learning. The two by far most agreed-on statements in this section refer to this analytical category. Less problems seem to have been present when it comes to technical equipment, and technical operation. Nonetheless, around $15 \%$ of the whole sample indicated the need for an own computer, and issues with regards to internet connection are generally more agreed-on by $30 \%$ of the sample.

\subsection{Advantages and disadvantages of digital learning tool use}

In addition to indicating their agreement to statements about noticed changes of behaviour, as well as their experience with the digital learning tools in use, university students were also asked to assess advantages and disadvantages of digital learning tool use during the current COVID-19 pandemic.

The biggest advantage of digital learning tool use during the COVID-19 pandemic, as perceived by students, is that they enable students to continue education from a distance, with a mean value of slider placement at 80.83 (SD 25.46). It is followed by the statement that they can develop their digital skills and competences with a mean value of 71.44 (SD 25.82), with $80 \%$ of respondents placing the slider on values between 60 and 100. The average student seems to be rather neutral towards the statement that more engaging learning materials can be used, with a mean value 52.43 (SD 31.62), and almost $20 \%$ completely or rather disagreeing, placing the slider on values below 20 out of 100 . On the other hand's side, $20 \%$ of students rather or completely agreed with the statement, with values above 80 out of 100 . Almost $40 \%$ of students rather or completely agreed with the statement that students are able learn at their own pace, with a mean value of agreement of 67.20 (SD 30.94) out of 100. Only roughly $11 \%$ 
completely or rather disagreed with this statement, placing the slider on values below 20 out of 100. Similarly, students rather agreed with being able to combine learning methods with a mean value of slider placement at 64.21 (SD 28.54).

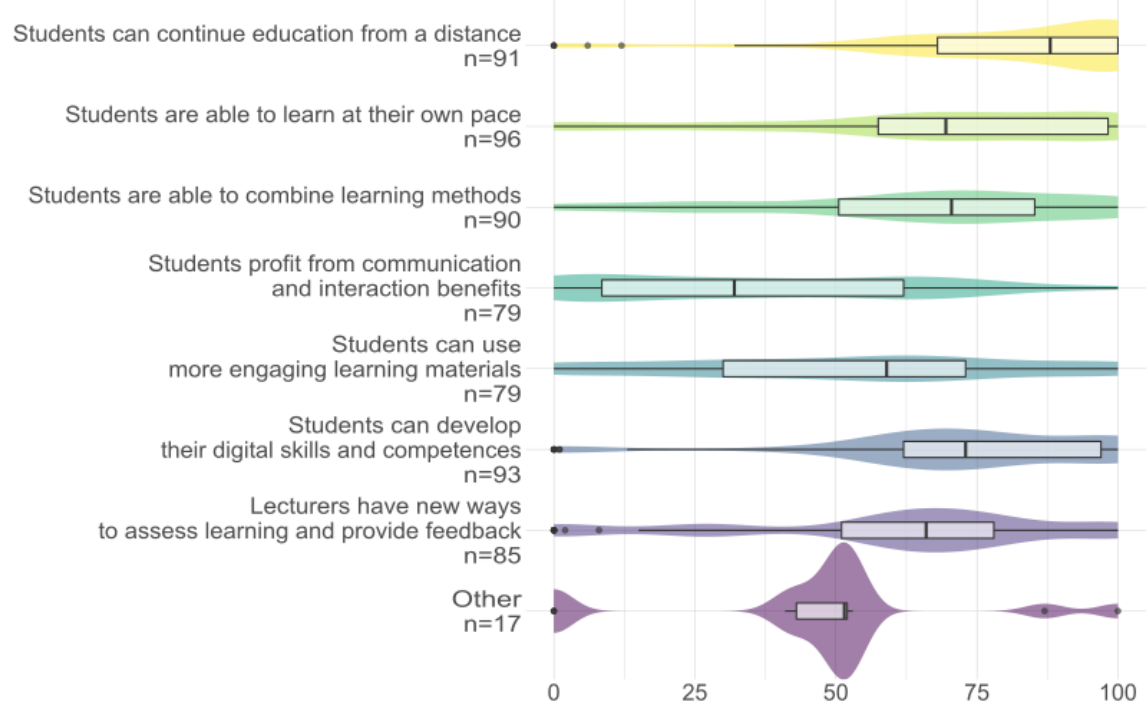

Fig. 8. Advantages of digital learning tool use during the COVID-19 pandemic Verbal anchors 'Do not agree at all' at 0 and 'Completely agree' at 100

The least agreed-on statement is that students profit from communication and interaction benefits, with a mean value of 36.59 (SD 29.29). More than $35 \%$ of students placed the slider on values between 0 and 20 out of 100, indicating to rather or completely disagree with this statement, and opposed to only roughly $4 \%$ rather or completely agreeing, with slider placements between 80 and 100. Less than $20 \%$ of students chose to indicate agreement to other advantages of digital learning tool use during the pandemic, but only one student placed the slider on a value higher than 80 out of 100 . The majority of students placed the slider on values between 41 and 53. It follows, that only few examples of perceived other advantages are indicated. The two provided examples include not having to commute to the university and back, as well as more free time.

The biggest disadvantage of digital learning tool use, as indicated by university students, is the lack of face-to-face interaction/communication, with the mean value of agreement being 85.52 (SD 19.07). Roughly $70 \%$ of respondents placed the slider on values higher than 80 out of 100 , whereas merely $1 \%$ placed it on values lower 
than 20. The second most agreed-on disadvantage of tool use is the presence of more distractions, with a mean agreement value of 78.48 (SD 23.75). This result is consistent with the most agreed-on statement with respect to change of behaviour, namely that it is harder to focus on the task at hand at home. Over $70 \%$ of students rather or completely agreed with this statement, making it the most prominent noticed change of behaviour.

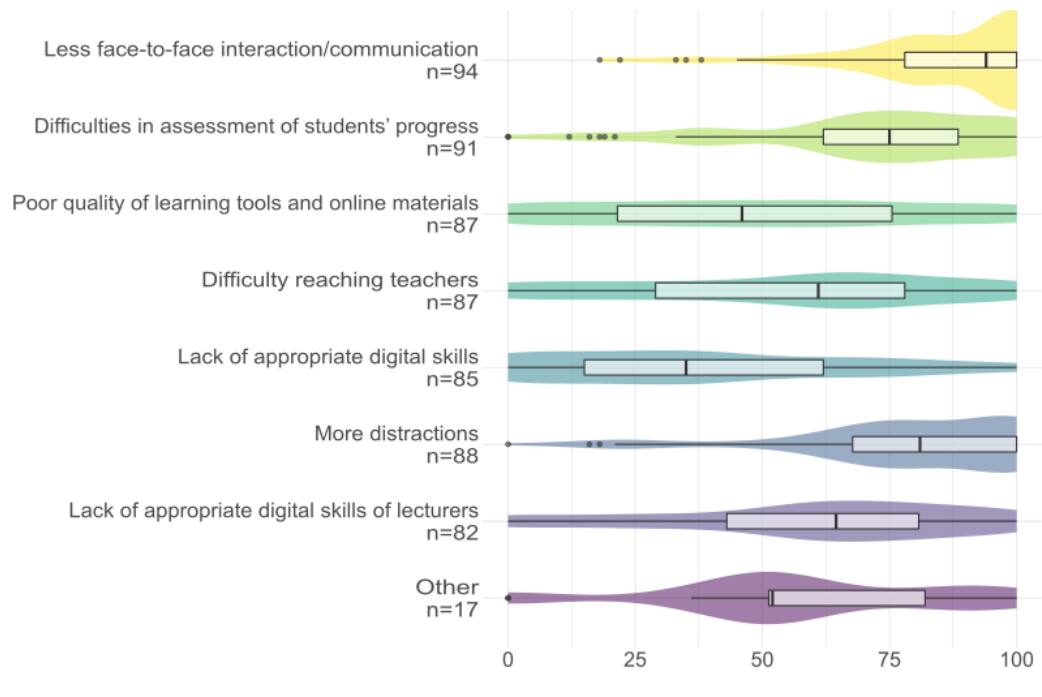

Fig. 9. Disadvantages of digital learning tool use during the COVID-19 pandemic Verbal anchors 'Do not agree at all' at 0 and 'Completely agree' at 100

Lack of appropriate skills of lecturers are also indicated as disadvantage of digital learning tool use with a mean value of slider placement at 60.06 (SD 23.75), and appear to constitute a bigger disadvantage than the students' own digital skills, with the mean value of agreement being merely 37.80 (SD 30.25).

In the section of disadvantages of digital learning tool use, similarly to the section of advantages, less than $20 \%$ of students show agreement to the statement that other disadvantages than the ones already stated exist. Yet, compared to the section of advantages, higher agreement values can be evidenced, with about $30 \%$ of respondents placing the slider on values above 80 out of 100, and additionally provide notably more examples of such disadvantages. These examples include the inability to meet teachers in person, technical issues like slow internet, or lack of an appropriate computer, as well as the lecturers' unpreparedness for online teaching and, consequently, the need for new teaching methods.

Summarising indicated advantaged and disadvantages of digital learning tool use during the COVID-19 pandemic, it appears that also in this section, communication 
is a central and recurring theme for students. The by far most agreed-on statement in the section of advantages and disadvantages combined refers the decline in face-to-face interaction and communication, and furthermore is a topic mentioned in the comments that students could leave voluntarily. Then again, one of the least agreed-on statements is that students can profit from communication and interaction benefits due to digital learning tools - indicating that there is an unfulfilled need. The students' digital skills, however, do not seem to pose a problem of digital learning tool use, and the further development of such skills is seen as an advantage of digital learning tool use by many of the respondents. Digital skills of lecturers, on the other hand's side, or rather lack thereof, are agreed-on to be a disadvantage.

\subsection{Qualitative data analysis}

Complimentary to the qualitative survey data, qualitative interviews with students of different fields of study at the University of Latvia were conducted via Skype and Google Meet in from December 2020 to February 2021. The present analysis includes both the qualitative survey data as well as the interview data. The qualitative data were analysed utilising a content analysis (Mayring, 2004), and yielded 24 different categories, which could be assigned to five emerging themes: Perceptions of distance learning, advantages of digital learning tool use, disadvantages of digital learning tool use, opportunities brought about by the distance learning mode, problems during distance learning.

3.8.1 Perceptions of distance learning The online delivery method brought about by the distance learning mode, for the vast majority of classes at various faculties, did not bring great changes to conventional class structure and content. "The only thing these [digital learning, author's note] tools are doing is changing the way I'm receiving information from the university. [...] I am not going to the lecture hall [to] hear what the lecturer is [telling] me, he [the lecturer] is using [Microsoft] Teams to [tell me]." According to interviewees, lecturers were generally not particularly resourceful in terms of adapting their pedagogical concept to the new delivery method. There are, however, exceptions to this general trend, as, according to the interviewees, some lecturers started using supplementary digital learning tools, like coding tools in Computer Science, or tools to foster interaction, such as Kahoot.

\subsubsection{Advantages and opportunities brought about by the distance learning mode} According to the interviewees, the time of distance learning generally saw an advance in digitisation of university education. Learning platforms are more widely used, as compared to the time before, and the recording of lectures have become common, according to students interviewed. There is a positive expectation that the implemented new teaching methods are here to stay, but also scepticism over whether this is a realistic hope. The qualitative data furthermore confirm the suspected diverging perceptions of the distance learning mode: For some students, distance learning was advantageous, as they could flexibly decide when and where to consume the online educational content, be it synchronous (live online teaching) or asynchronous (recorded lectures). This 
was suspected to be most beneficial to students who are employed, and students who are parents, as they did not need to commute to the university.

3.8.3 Disadvantages and problems during distance learning There are, however, also students who are struggling with decreased motivation, caused by lack of face-toface interaction with educators and peers, and/or lacking structure that on-site lectures offered. This lack of motivation was not always a result of changing internal motivation, but "external motivation", as a student explains: "I'd say [...] the inside motivation probably didn't change as much, but the outside [...] motivation that the university would pose [...] is probably lower." Another facet to be noted is, that communication with the professors and lecturers in times of on-site learning is regarded a "lowthreshold" communication, meaning that is easier to approach educators during or after class. In times of distance learning in an online setting, this is evidently experienced as harder. For some students, according to the gathered qualitative data, shifting classes to the online delivery mode has had an irretrievably detrimental effect, as it made impossible to carry out certain study activities, such as practical work in laboratories for Life science students, and residencies for Medicine students, as well as experimental work for Bachelor's or Master's theses.

Furthermore, students report that it is harder to focus in times of distance learning, as there was no quiet place to work available, or because they are more distracted, especially when having to convert their accommodation from "leisure-area" into "workingarea". Time management slightly worsened, according to the gathered qualitative data, not always because there was less time at hand, but due to the lacking structure students were used to from the times from on-site education. "I basically have to do my own thing all of the time [self-organise, author's note], which might not be [as] convenient $[\ldots]$ as you have to figure it out on your own." The increase in independence with regards to organisation was experienced as challenging. Another concomitant of the distance learning mode are problems concerning communication with the educational institutions. "I know that at some faculties, the communication is rocky, [...] the communication is slow and the faculty does not say what will happen. [...] The faculty is just silent, $[\ldots]$ the students just don't know what to do [...]." The qualitative data reveal that problems with the collation and communication of information occurred, which left students lacking guidance during distance learning.

\section{Limitations}

Some limitations of the present investigation arise from the cross-sectional study design: The collected information merely represents a snapshot of the different aspects affecting the students' experiences with the distance learning mode in the course of the COVID-19 pandemic, and do not allow inferences about causal relationships between variables. Additionally, and as addressed in the Results section, the present sample, in spite of all efforts, does not accurately depict the Latvian student population, and is biased towards undergraduate students and students of STEM (Science, Technology, Engineering, Mathematics) fields of study like Life Sciences, Mathematics, Computer 
Science and Engineering. While also students from study fields such as Humanities and Pedagogy, to name a few, filled out the survey, they constitute the minority. Rather than being representative of the whole Latvian student population, the results and conclusions of the present research are illustrative of students' experiences of learning during the COVID-19 pandemic. Another limitation arises from the mode of item presentation. When presented with the different items, the slider was positioned in the middle of the scale, possibly inviting respondents to place the slider on values close to the initial position. This might have led them to favour central values over those closer to the verbal anchor points left and right of the scale. Furthermore, it needs to be mentioned that self-observed assessments are subject to bias, and in this study, they were not counterbalanced, or corroborated with objective measures of the student's efficiency, time management or attainment, to name a few. Moreover, this study is exploratory in nature, and the items were developed by the author and do not constitute parts of standardised questionnaires. All the presented limitations factor into the findings of this study not being generalisable without reservation.

\section{Discussion}

Dealing with digital learning tools has become the new daily routine for university students as their classes were shifted to the distance learning mode early into the academic year 2020/21. The present exploratory study aims at providing an insight into students' digital learning tool use, their perceptions of the tools in use, as well as their needs and prospects with regards to education in times of distance learning. The present study yielded that the frequency of digital learning tool use in our sample increased across all of the different learning tool types and categories, as compared to the time before spring 2020. The most commonly used digital learning tool during the winter term 2020/21 featured live online teaching, via tools like Microsoft Teams and Zoom, followed by (recorded) videos of professors or lecturers and social media for learning. Social media for learning were found to be the most frequently used tool, with more than a third using them daily for learning purposes. The biggest increase of use was evidenced for live online teaching tools, videos of professors and lecturers, and online learning materials provided by different websites. The provision of recorded lectures was not common at Latvian universities before switching to distance learning mode during the COVID19 pandemic, and qualitative data suggest that students have expectations for them to be available in the future. The present study furthermore revealed that an application designed for communication purposes, namely WhatsApp, is the most frequently used digital learning tool, hereby reproducing similar findings by Rahiem (2020).

The most pronounced changes of behaviour noticed by students in the present sample were their worsened focus, followed by feeling less motivated or engaged than in regular classes at university. The worsened focus and decreased motivation experienced by students goes in line with similar findings of Chinese students (Sun et al., 2020) and students in the United States (Aguilera-Hermida, 2020). The gathered qualitative data reveal that the underlying factors contributing to worsened focus of students in our sample are manifold: some students report that they do not have a quiet place to study, 
and indicate other people in their household, such as children, interfering. Then again, others struggle to convert the available space from "leisure-area" into "working-area", and report struggling with more distractions. It could be hypothesised that the students ascribe the reported lack of focus to some degree to the distance learning mode using digital learning tools, as they indicated more distractions to be one of the most agreedon disadvantages of digital learning tool use during the COVID-19 pandemic. However, the mentioned distractions can have various sources, and might also be explained by the student's inadequate study environment or by individual factors. Similar reports of increased distractions could also be evidenced for online learning in pre-pandemic times (Tichavsky et al., 2015).

Another important factor to bear in mind is that a sizeable fraction of students almost a third of the sample - rather or completely agreed with feeling scared, hinting towards feelings of fear and anxiety being a non-negligible phenomenon amongst university students in times of distance learning. The percentage of students reporting to feel scared in this sample is higher than in similar studies, such as Aguilera-Hermida (2020), where less than $10 \%$ of respondents reported negative emotions such as anxiety, sadness, and worry; and also Rahiem (2020) evidences feelings of confusion, depression and isolation in her sample. Unlike the present study, however, Aguilera-Hermida (2020) did not explicitly ask about these negative emotions in relation to remote learning, which might explain some of the discrepancy. In their study, Cao et al. (2020) explored the prevalence of anxiety using a standardised scale in a sample of college students in China and found that around $25 \%$ of student experienced at least moderate anxiety, calling for the provision of psychological assistance during health crises like the COVID-19 pandemic. The importance of considering student's metal state with respect to the remote learning is also highlighted by Bao (2020).

When asked about their overall satisfaction with the distance learning mode, the students in the sample reported an only weak positive perception, with a mean value slightly above 50 out of 100 . For the three most the most represented study fields, overall satisfaction was highest for students of Life sciences, followed by students of Pedagogy, and lowest for Mathematics students. In the present sample, higher ratings of overall satisfaction with the distance learning mode are strongly associated with better time management, better focus on tasks at hand and increased motivation. Then again, worse time management and motivational issues are associated with lower ratings of overall satisfaction with the distance learning mode. Similar associations between motivation and perception of remote learning could also be evidenced by Aguilera-Hermida (2020) for university students in the United States.

\subsection{Communication and interaction as important factors}

Communication emerged as an important factor in various categories of analysis of the present study: The most prominent disadvantage of digital learning tool use in times of distance learning, as obtained by the quantitative survey, refers to the decline in (face-to-face) interaction and communication, and is also a recurring topic in the qualitative data. The investigation by Rahiem (2020) evidences this as well, with students 
experiencing learning as ineffective without discussion. Moreover, Bawa (2020) and Aguilera-Hermida (2020) stress interaction as a motivating factor for students, whereas a lack thereof is linked to perceptions of decreased efficiency (Baber, 2021). In a qualitative study about preferences of students with regards to online versus presential learning, Tichavsky et al. (2015) found that interaction with peers and educators to be the most prominent theme impacting preference for face-to-face learning, and was linked to increased enthusiasm and motivation, as well as better focus. Furthermore, it can be noted that the only feature that was significantly associated with higher satisfaction with the digital learning mode was that the tools in use provided feedback and tips for the student $(r=.244, p<0.05)$, meaning that they had an interactive component.

However, one of the least agreed-on statements is that students profit from communication and interaction benefits due to digital learning tool use during distance learning, which, together with the finding that the tools in use generally do not foster collaboration, indicates that there is an unfulfilled need with regards to communicative and interactive features of the digital learning tools in use. These shortcoming with regards to communication, as perceived by students in this sample, can be hypothesised to generalise to other populations in the educational sphere, as results of Daniela, Rūdolfa, \& Rubene (in press) suggest. When assessing the most commonly used learning materials in Latvian schools, the authors came to the conclusion that communication (between student-material, student-teacher, as well as student-student) is a neglected facet by the designers of the tools in use. In the light of the ascribed importance of knowledge sharing via interaction and collaboration for learning and knowledge creation (Al-Kurdi et al., 2018), these findings are especially noteworthy. Digital learning tools should hence provide features that facilitate interaction, communication and collaboration between students as well as educators, which is particularly emphasised by their increasing importance for knowledge sharing among the younger generations (Asterhan and Bouton, 2017).

Moreover, when asked about their needs, students furthermore expressed shortcomings with regards to communication, for one thing concretely with their professors and lecturers, but also in general concerning communication about the structure of classes and learning goals. Indeed, professor support and caring were positively associated with better learning and educational outcome (Buttler et al., 2021), and also Bawa (2020) found communication, both with the professor or lecturer, as well as generally about structure and deliverables of the courses to be key factors shaping the students experience of remote learning. This is crucial because clarity concerning structure and learning goals have been shown to impact learning and grades (Buttler et al., 2021), and lack thereof furthermore constitutes a prominent barrier to online learning (Muilenburg and Berge, 2005). Communication emerged as a recurring theme in various categories of analysis, highlighting the importance of communication not only amongst students but also with educators and institutions. The results of this exploratory study highlight that motivation and engagement, as well as communication and interaction are important factors with regards to student's perceptions of and attitudes towards the distance learning mode. This is important as a positive attitude is traditionally linked to suc- 
cess in learning in various domains (Chen et al., 2018; Hashemian and Heidari, 2013), and also specifically in the online setting (Prior et al., 2016; Aguilera-Hermida, 2020). However, it is not yet clear how these attitudes impact learning success in the present case of (emergency) remote learning during the COVID-19 pandemic. Especially the surprising findings by Iglesias-Pradas et al. (2021), evidencing that improvement of attainment was higher in courses where educators perceived the students' attitudes to be more negative, raises questions and calls for further research on factors impacting students' attainment during Emergency Remote Teaching and distance or remote learning.

Technology will play a pivotal role in future education: students in the present sample are of like mind ascribing high importance to digital learning tools for their future education. Moreover, the qualitative data reveal that students saw an advance of digitisation in their institutions the time of distance learning, and expressed the hope that it is a change of lasting nature. Understanding the needs, demands and specifications of future users is hence crucial. The present exploratory research undertook first steps into understanding digital learning tool use during the COVID-19 pandemic, and provides first evidence for the Latvian student population. The present study aimed at obtaining an overview of students' experiences with digital learning tools during the COVID-19 pandemic in Latvia, it does not claim to provide a comprehensive analysis.

\section{Acknowledgements}

This project has received funding from the European Union's Horizon 2020 research and innovation programme under the Marie Skłodowska-Curie grant agreement No 857897. The author wishes to thank Solvita Umbraško, Līga Zariņa, and, most of all, Jurgis Škilters for their advice and support.

\section{References}

Aboagye, E., Yawson, J. A., Appiah, K. N. (2021). Covid-19 and e-learning: The challenges of students in tertiary institutions, Social Education Research pp. 1-8.

Aguilera-Hermida, A. P. (2020). College students' use and acceptance of emergency online learning due to covid-19, International Journal of Educational Research Open 1, 100011.

Al-Kurdi, O., El-Haddadeh, R., Eldabi, T. (2018). Knowledge sharing in higher education institutions: a systematic review, Journal of Enterprise Information Management .

Anohina, A. (2005). Analysis of the terminology used in the field of virtual learning, Journal of Educational Technology \& Society 8(3), 91-102.

Asterhan, C. S., Bouton, E. (2017). Teenage peer-to-peer knowledge sharing through social network sites in secondary schools, Computers \& Education 110, 16-34.

Baber, H. (2021). Social interaction and effectiveness of the online learning-a moderating role of maintaining social distance during the pandemic covid-19, Asian Education and Development Studies

Bao, W. (2020). Covid-19 and online teaching in higher education: A case study of peking university, Human Behavior and Emerging Technologies 2(2), 113-115.

Bass, B. M., Cascio, W. F., O'connor, E. J. (1974). Magnitude estimations of expressions of frequency and amount., Journal of Applied Psychology 59(3), 313. 
Bawa, P. (2020). Learning in the age of sars-cov-2: A quantitative study of learners' performance in the age of emergency remote teaching, Computers and Education Open .

Bocklisch, F., Bocklisch, S. F., Krems, J. F. (2012). Sometimes, often, and always: Exploring the vague meanings of frequency expressions, Behavior Research Methods 44(1), 144-157.

Buttler, T., George, D., Bruggemann, K. (2021). Student input on the effectiveness of the shift to emergency remote teaching due to the covid crisis: Structural equation modeling creates a more complete picture, International Journal of Educational Research Open 2, 100036.

Cao, W., Fang, Z., Hou, G., Han, M., Xu, X., Dong, J., Zheng, J. (2020). The psychological impact of the covid-19 epidemic on college students in china, Psychiatry research 287, 112934.

Central Statistical Bureau (2021). Breakdown of students, enrolments and graduates in higher education institutions and colleges by age, sex and educational attainment, Website. Retrieved from:http://data1.csb.gov.lv/pxweb/en/sociala/sociala__izgl_ _augstsk/?rxid=06555a82-37b7-4029-aa36-a4bbce999b16\&tablelist=true last accessed April 4, 2021.

Chen, L., Bae, S. R., Battista, C., Qin, S., Chen, T., Evans, T. M., Menon, V. (2018). Positive attitude toward math supports early academic success: Behavioral evidence and neurocognitive mechanisms, Psychological science 29(3), 390-402.

Chen, T., Peng, L., Yin, X., Rong, J., Yang, J., Cong, G. (2020). Analysis of user satisfaction with online education platforms in china during the covid-19 pandemic, Healthcare, Vol. 8, Multidisciplinary Digital Publishing Institute, p. 200.

Cicchetti, D. V., Shoinralter, D., Tyrer, P. J. (1985). The effect of number of rating scale categories on levels of interrater reliability: A monte carlo investigation, Applied Psychological Measurement 9(1), 31-36.

Crawford, J., Butler-Henderson, K., Rudolph, J., Malkawi, B., Glowatz, M., Burton, R., Magni, P., Lam, S. (2020). Covid-19: 20 countries' higher education intra-period digital pedagogy responses, Journal of Applied Learning \& Teaching 3(1), 1-20.

Daniela, L., Rubene, Zanda Rūdolfa, A. (in press). Results of the evaluation of learning platforms and digital learning materials, Remote Learning Courses Design and Delivery: The Instructor Perspective .

Gonzalez, T., De La Rubia, M., Hincz, K. P., Comas-Lopez, M., Subirats, L., Fort, S., Sacha, G. (2020). Influence of covid-19 confinement on students' performance in higher education, PloS one 15(10), e0239490.

Hashemian, M., Heidari, A. (2013). The relationship between 12 learners' motivation/attitude and success in 12 writing, Procedia-Social and Behavioral Sciences 70, 476-489.

Hodges, C., Moore, S., Lockee, B., Trust, T., Bond, A. et al. (2020). The difference between emergency remote teaching and online learning, Educause review 27, 1-12.

Huang, R. (2014). Rqda: R-based qualitative data analysis, $R$ package version $0.2-7$.

Iglesias-Pradas, S., Hernández-García, Á., Chaparro-Peláez, J., Prieto, J. L. (2021). Emergency remote teaching and students' academic performance in higher education during the covid-19 pandemic: A case study, Computers in Human Behavior 119, 106713.

Jamieson, S. (2004). Likert scales: How to (ab) use them?, Medical education 38(12), 1217 1218.

Mayring, P. (2004). Qualitative content analysis, A companion to qualitative research 1(2), 159176.

Mei, X. Y., Aas, E., Medgard, M. (2019). Teachers' use of digital learning tool for teaching in higher education, Journal of Applied Research in Higher Education .

Morse, J. M. (2003). Principles of mixed methods and multimethod research design, Handbook of mixed methods in social and behavioral research 1, 189-208.

Muilenburg, L. Y., Berge, Z. L. (2005). Student barriers to online learning: A factor analytic study, Distance education 26(1), 29-48. 
Newstead, S. E., Collis, J. M. (1987). Context and the interpretation of quantifiers of frequency, Ergonomics 30(10), 1447-1462.

Preston, C. C., Colman, A. M. (2000). Optimal number of response categories in rating scales: reliability, validity, discriminating power, and respondent preferences, Acta psychologica 104(1), 1-15.

Prior, D. D., Mazanov, J., Meacheam, D., Heaslip, G., Hanson, J. (2016). Attitude, digital literacy and self efficacy: Flow-on effects for online learning behavior, The Internet and Higher Education 29, 91-97.

Public Broadcasting of Latvia (2020a). First case of covid-19 coronavirus confirmed in latvia, Website. Retrieved from: https://eng.lsm.lv/article/society/health/ first-case-of-covid-19-coronavirus-confirmed-in-latvia.a350338/; last accessed on 27.04.2021.

Public Broadcasting of Latvia (2020b). Latvian government announces widespread measures to contain coronavirus, Website. Retrieved from: https://eng.lsm.lv/article/society/ health/latvian-government-announces-widespread-measures-to-contain protect \discretionary $\{\backslash$ char $\backslash$ hyphenchar $\backslash$ font $\}\{\}\{\}$ coronavirus . a351529/; last accessed 27.04.2021.

Rahiem, M. D. (2020). The emergency remote learning experience of university students in indonesia amidst the covid-19 crisis, International Journal of Learning, Teaching and Educational Research 19(6), 1-26.

Reips, U.-D., Funke, F. (2008). Interval-level measurement with visual analogue scales in internet-based research: Vas generator, Behavior research methods 40(3), 699-704.

Roster, C. A., Lucianetti, L., Albaum, G. (2015). Exploring slider vs. categorical response formats in web-based surveys, Journal of Research Practice 11(1), D1-D1.

Sun, L., Tang, Y., Zuo, W. (2020). Coronavirus pushes education online, Nature Materials 19(6), 687-687.

Tichavsky, L. P., Hunt, A. N., Driscoll, A., Jicha, K. (2015). " it's just nice having a real teacher": Student perceptions of online versus face-to-face instruction., International Journal for the Scholarship of Teaching and Learning $\mathbf{9}(2), \mathrm{n} 2$.

UNESCO (2021). Education: From disruption to recovery, Website. Retrieved from: https: //en. unesco.org/covid19/educationresponsel; last accessed on 27.04.2021.

Weijters, B., Cabooter, E., Schillewaert, N. (2010). The effect of rating scale format on response styles: The number of response categories and response category labels, International Journal of Research in Marketing 27(3), 236-247.

World Health Organization (2020). Who director-general's opening remarks at the media briefing on covid-19 - 11 march 2020, Website. Retrieved from: https://www.who.int/director-general/speeches/detail/ who-director-general-s-opening-remarks-at-the-media-briefing- $\backslash$ on-covid-19---11-march-2020; last accessed on 27.04.2021.

Received May 10, 2021 , revised August 9, 2021, accepted August 21, 2021 